\title{
Analysis of Adult Nephrectomies at the Komfo Anokye Teaching Hospital, Kumasi, Ghana
}

\author{
Kwaku Otu-Boateng1, George Amoah ${ }^{1}$, Kwaku Addai Arhin Appiah ${ }^{*}$, Roland Azorliade ${ }^{1}$, \\ Christian Kofi Gyasi-Sarpong1,2, Patrick Opoku Manu Maison³, Samuel Kodzo Togbe1, \\ John Boakye Addae', Charles Kwame Adofo4, Isaac Opoku Antwi', \\ Benjamin Twumasi-Frimpong1, Richard Kofi Ametih ${ }^{1}$
}

\author{
${ }^{1}$ Department of Surgery, Komfo Anokye Teaching Hospital, Kumasi, Ghana \\ ${ }^{2}$ Department of Surgery, School of Medical Sciences and Dentistry, KNUST, Kumasi, Ghana \\ ${ }^{3}$ Department of Surgery, School of Medical Sciences, UCC, Cape Coast, Ghana \\ ${ }^{4}$ Surgery Department, Seventh Day Adventist Hospital, Dominase, Ghana \\ Email: addaiarhin@yahoo.com
}

How to cite this paper: Otu-Boateng, K., Amoah, G., Appiah, K.A.A., Azorliade, R., Gyasi-Sarpong, C.K., Maison, P.O.M., Togbe, S.K., Addae, J.B., Adofo, C.K., Antwi, I.O, Twumasi-Frimpong, B. and Ametih, R.K. (2020) Analysis of Adult Nephrectomies at the Komfo Anokye Teaching Hospital, Kumasi, Ghana. Open Journal of Urology, 10, 93-100.

https://doi.org/10.4236/oju.2020.104011

Received: November 1, 2019

Accepted: March 27, 2020

Published: March 30, 2020

Copyright ( 2020 by author(s) and Scientific Research Publishing Inc. This work is licensed under the Creative Commons Attribution International License (CC BY 4.0).

http://creativecommons.org/licenses/by/4.0/ (c) (i) Open Access

\begin{abstract}
Objective: To evaluate open nephrectomies performed in adults over a five year period at the Komfo Anokye Teaching Hospital (KATH) and to compare our experience with findings in the literature. Materials and Methods: This was a prospective, cross-sectional, hospital based study of all adults undergoing nephrectomy from October 2012 to September 2017 at KATH. We obtained data on patient demographics, clinical presentation, laboratory and imaging results, laterality of the disease, and indication for nephrectomy, complications and histopathology of nephrectomy specimen. The data was analyzed using PASW Statistics for Windows, Version 19.0. Chicago: SPSS Inc. Results: Thirty three (33) adult nephrectomies were performed over the study period. There were 18 males $(54.50 \%)$ and 15 females (45.50\%) with an age range of 16 years to 80 years. The modal age range for renal malignancies was 31 - 40 years accounting for $36.40 \%$ of adult nephrectomies. Flank pain (75.80\%), haematuria $(54.60 \%)$ and flank mass $(51.50 \%)$ were the predominant presenting complaints. Malignant renal tumours accounted for 22 (66.70\%) of the nephrectomies followed by neglected Pelvi-Ureteric Junction Obstruction (PUJO) -7 (21.20\%); two (6.10\%) nephrectomies were due to trauma and one $(3.00 \%)$ for emphysematous pyelonephritis. Conclusion: Renal cell carcinoma constitutes the main indication for adult nephrectomy at KATH followed by neglected PUJO. Most of the patients with renal tumours were young and also presented late.
\end{abstract}

\section{Keywords}

Adult, Nephrectomy, Renal Cell Carcinoma, Kidney, Komfo Anokye 
Teaching Hospital

\section{Introduction}

Nephrectomy forms an important part of the workload of the urologist; it may be simple or radical. A simple nephrectomy is indicated in patients with symptomatic benign non-functioning kidney and trauma. Radical nephrectomy is the gold standard for treating resectable renal malignancies [1] [2].

Incidental detection of renal tumours has increased in asymptomatic patients in the advanced countries due to the routine use of ultrasonography and Computed Tomography (CT) scan for abdominal and chest complaints [3] whereas patients continue to present with late disease in developing countries [4].

The indications for nephrectomy vary from place to place and so too does the surgical technique employed [5]. In developed countries, nephrectomy is mainly carried out laparoscopically or is robot assisted [6]. This offers early recovery and return to work, however, its use is associated with higher costs [6]. In Sub-Saharan Africa, open nephrectomy still remains the main surgical approach [7]. This offers complete resection even for bulky tumours and can be carried out in any resource limited facility. It is however associated with increased postoperative pain, morbidity and poor cosmesis [8].

Complications following nephrectomy are not uncommon and may differ based on indications and surgical technique used. Nephrectomies for malignant conditions are associated with more complications than nephrectomies performed for benign renal conditions [9] [10].

The Komfo Anokye Teaching Hospital (KATH) is a major referral center serving the middle and northern belts of Ghana. Although open nephrectomy is routinely carried out in the hospital, no formal data has been reported from the institution.

The purpose of this study is to describe the clinico-pathological features of adult patients who had open nephrectomy, the indications, complications and the short term outcomes at KATH over a five-year period and to compare our experience with findings in the literature.

\section{Materials and Methods}

This was a prospective, cross sectional, hospital based study of all consenting adults undergoing nephrectomy from October 2012 to September 2017 at KATH.

Over the five year period, a total of 33 adult open nephrectomies were carried out at the Urology Unit of the Komfo Anokye Teaching Hospital. Data collected included patients' age, gender, clinical presentation, results of laboratory and imaging investigations, laterality of the disease and indications for nephrectomy. It also involved the record of complications including peri-operative mortality and histopathology results for all the patients. The patients were radiologically evaluated using abdominal ultrasonography, intravenous pyelogram, contrast enhanced CT scan and radioisotope renal scan to assess differential renal func- 
tion where necessary. Simple nephrectomy was carried out for patients with benign renal disease whilst radical nephrectomy and nephroureterectomy were carried out for those with malignant renal tumours and urothelial tumours of the renal pelvis respectively. All patients were followed up for a minimum duration of one year.

The data was analyzed using PASW Statistics for Windows, Version 19.0. Chicago: SPSS Inc.

Patients aged 16 years and above who had nephrectomy done during the study period were eligible for the study. Ethical approval was obtained from the Committee for Human Research and Publication Ethics of the Kwame Nkrumah University of Science and Technology and the Komfo Anokye Teaching Hospital.

\section{Results}

During the study period, a total of 33 adult open nephrectomies were performed. There were 18 males (54.50\%) and 15 females (45.50\%) giving a male to female ratio of 1.2:1.

The age range was from 16 years to 80 years with the modal age group being 31 - 40 years $(24.24 \%)$.

Out of the 33 patients, malignant renal tumours accounted for 22 (66.70\%) of the nephrectomies; this was followed by benign non-functioning kidneys as a result of neglected Pelvi-Ureteric Junction Obstruction (PUJO) 21.21\%; and trauma $6.90 \%$ (Table 1 ).

The malignant renal tumors were equally distributed in a ratio of 1:1 amongst the sexes.

The modal age range for renal malignancies was 31 - 40 years which accounted for $36.36 \%$ of nephrectomies done for renal malignancies (Table 2).

Table 1. Indications for nephrectomy.

\begin{tabular}{ccc}
\hline Indication & Frequency & \% frequency \\
\hline Malignant tumours & 22 & 66.67 \\
Neglected PUJO & 7 & 21.21 \\
Trauma & 2 & 6.06 \\
Benign Tumours & 1 & 3.03 \\
Emphysematous pyelonephritis & 1 & 3.03 \\
\hline
\end{tabular}

Table 2. Age distribution for renal malignancies.

\begin{tabular}{ccc}
\hline Age distribution for renal malignancies & Frequency & \% Frequency \\
\hline$<21$ & 2 & 9.09 \\
$21-30$ & 2 & 9.09 \\
$31-40$ & 8 & 36.36 \\
$41-50$ & 5 & 22.73 \\
$51-60$ & 4 & 18.18 \\
$61-70$ & 1 & 4.55 \\
\hline
\end{tabular}


Flank pain, occurring in $75.76 \%$ of the patients, haematuria- $54.55 \%$ and flank mass $-51.50 \%$ were the predominant presenting complaints (Table 3, Figure 1).

\subsection{Laterality of Nephrectomies}

A total of 19 (57.58\%) left and 14 (42.42\%) right nephrectomies were performed. There were 11 each of left and right nephrectomies for renal malignancies. For benign renal lesions and trauma to the kidneys, there were more left-sided nephrectomies carried out than were performed on the right- 8 versus 3 .

\subsection{Complications}

Peri-operative complications of the surgery included avulsion of renal artery with massive hemorrhage -1 (3.0\%), laceration of inferior vena cava (IVC) -1 (3\%), bowel injury-1 (3.0\%), and superficial surgical site infections-3 (9.0\%). There was $1(3.0 \%)$ post-operative mortality.

\subsection{Histology of the Tumours}

Renal cell carcinoma (RCC) accounted for 17 (73.91\%) of the tumours and all were of the clear cell subtype. This was followed by transitional cell carcinoma of the renal pelvis $3(13.04 \%)$, Wilm's tumour $2(8.70 \%)$ and oncocytoma $1(4.35 \%)$ (Table 4). Of the two Wilm's tumour cases, one was a 16 year old male and the other, a 19 year old female.

Table 3. Clinical presentation.

\begin{tabular}{cc}
\hline CLINICAL PRESENTATION & Number (\%) \\
\hline Flank pain & $25(75.76)$ \\
Flank mass & $17(51.50)$ \\
Hematuria & $18(54.55)$ \\
Varicocele & $2(6.06)$ \\
Incidental finding & $1(3.03)$
\end{tabular}

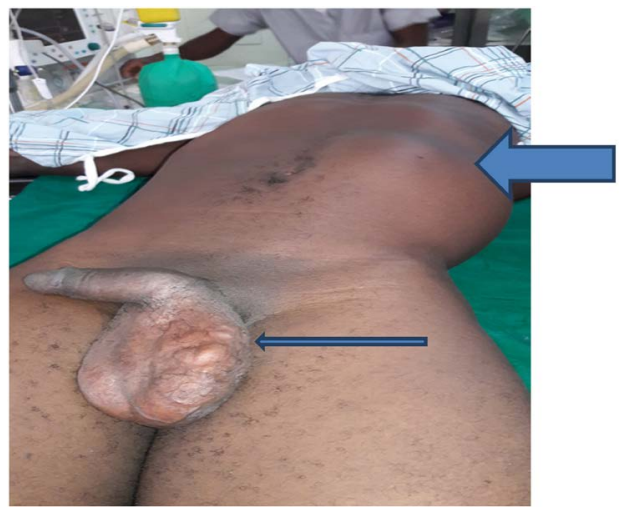

Figure 1. Patient with flank mass (Big Arrow) from left renal tumour and left varicocele (Small arrow) being prepared for nephrectomy. 
Table 4. Histology of the tumours.

\begin{tabular}{ccc}
\hline Histology & Frequency & \% Frequency \\
\hline Renal cell carcinoma & 17 & 73.91 \\
Transitional cell & 3 & 13.04 \\
Wilms Tumour & 2 & 8.70 \\
Oncocytoma & 1 & 4.35 \\
\hline
\end{tabular}

\section{Discussion}

Globally, the indications for nephrectomy vary from place to place [11]. The predominant indication for nephrectomy in this study was for renal tumours. Renal malignancies accounted for $66.70 \%$ of all indications (Table 1). This is consistent with studies from Nigeria and Norway where renal malignancies accounted for $67.30 \%$ and $68.00 \%$ of all nephrectomies respectively [4] [9].

In a similar study in Accra, Ghana, by Kyei et al., renal malignancy accounted for $54 \%$ of all nephrectomies [1]. However, this study contrasts with findings from India, Pakistan and Jordan where benign conditions of the kidney accounted for the majority of nephrectomies [5] [11] [12].

In the case of Pakistan, Rafique et al. found that the major indication for nephrectomy was for non-functioning kidneys from renal stone disease $53.30 \%$, chronic pyelonephritis $20.00 \%$, neglected PUJO $16.00 \%$ and $7.60 \%$ for renal tuberculosis. Only $23.00 \%$ were as a result of renal malignancy [5].

Similarly in India, Biswajit et al. found that $62.50 \%$ of nephrectomies were performed for benign conditions including neglected PUJO and renal stone disease. Malignant renal disease accounted for $37.50 \%$ of nephrectomies in their series [11].

Renal cell carcinoma is primarily a disease of the aged, typically occurring in the sixth and seventh decades of life [13] [14]. In this study however, the modal age range for renal malignancies was 31 - 40 years which accounted for $36.36 \%$ of nephrectomies performed for renal malignancies (Table 2) with the mean age being 43.80 years. Malignant renal tumours occurred in females at an earlier age of 39.00 years compared to 43.60 years in males. This is similar to a study in Nigeria by Ahmed et al. [15].

The male to female ratio for renal malignancies was 1:1 consistent with findings from Accra [1]. However in sub-Saharan Africa, there is a preponderance of renal tumours in females [16].

On the other hand, in most other studies from elsewhere, there was a male preponderance [7] [17] [18].

In our part of the world, renal tumours present in the advanced stage with flank mass, flank pain and haematuria or a combination of the above symptoms (Table 3). In this study, 35\% of the patients with renal tumours presented with the triad of haematuria, flank pain and flank mass similar to the $36 \%$ by Tijani et al. [19]. 
In addition to this triad, one male patient with left renal tumour presented with a left varicocele (Figure 1). These findings are similar to studies in other developing countries [7] [20].

In contrast, in the developed world, most renal tumours are picked incidentally [21].

Renal cell carcinoma accounted for 17 (73.91\%) of the malignant tumours followed by transitional cell carcinoma of the renal pelvis 3 (13.04\%) (Table 4).

The predominant histologic subtype of the Renal Cell Carcinomas (RCC) in this study was the clear cell variant. Clear cell RCC is the most common adult RCC, representing $70 \%$ of all RCCs [13].

There were $2(8.70 \%)$ cases of Wilm's tumour which were unexpected due to the rarity of adult Wilm's tumour [22] and its mainly reported on as case reports in literature.

The next commonest indication for nephrectomy in our center was non-functioning kidney as a result of neglected PUJO (Table 1) which accounted for $24.10 \%$ of all nephrectomies. This is similar to findings from rural India where $25.30 \%$ of nephrectomies were on account of neglected PUJO (8). However, this contrasts with findings from Eastern Africa where the predominant benign indication for nephrectomy was non- functioning kidney due to stone disease [17] and in Accra where the most predominant benign indication for nephrectomy was renal cystic disease (1).

In Nigeria $6.7 \%$ of nephrectomies were performed on account of trauma (5). In our study, a similar percentage (6.9\%) of nephrectomies were due to trauma (Table 1).

One person in the present study had nephrectomy on account of left emphysematous pyelonephritis (Table 1) but died in the immediate post-operative period from overwhelming sepsis. The mortality rate for emphysematous pyelonephritis has been estimated to be above $40.00 \%$, primarily owing to septic complications [23].

All nephrectomies in this series were done with the open approach. This is the mainstay of treatment in our sub region [16]. None of our patients with renal tumours had partial nephrectomy performed as is done in many endowed centers [21]

This study recorded a mortality rate of $3.00 \%$. This is equivalent to the $0.6 \%$ to $3.6 \%$ mortality rate recorded in literature for nephrectomy for localised disease [24].

\section{Conclusion}

The major indication for adult nephrectomy was renal cell carcinoma followed by neglected PUJO. Most of the patients with renal tumours were young and also presented late. Histological examination of nephrectomy specimens confirmed renal cell carcinoma as the commonest renal malignant tumour. We recommend further studies to elucidate the cause(s) for the relatively younger age of patients 
with renal cell carcinoma in our center.

\section{Conflicts of Interest}

The authors declare no conflicts of interest regarding the publication of this paper.

\section{References}

[1] Kyei, M.Y., Klufio, G.O., Mensah, J.E., Gyasi, R.K., Gepi-Attee, S. and Ampadu, K. (2015) Nephrectomy in Adults: Experience at the Korle Bu Teaching Hospital, Accra, Ghana. Saudi Journal of Kidney Disease and Transplantation, 26, 638-642.

http://www.sjkdt.org/article.asp?issn=1319-2442;year=2015; volume=26;issue=3; spa ge $=638$; epage $=642$;aulast $=$ Kyei https://doi.org/10.4103/1319-2442.157438

[2] Sreedhar, V., Paul, M., Sirisha, O., Shivaram, P., Sudhir, N., et al. (2015) Pathological Study of Elective Nephrectomies for a Two Year Period. International Journal of Research in Medical Sciences, 3, 1496-1500. https://doi.org/10.18203/2320-6012.ijrms20150174

[3] Nguyen, M.M., Gill, I.S. and Ellison, L.M. (2006) The Evolving Presentation of Renal Carcinoma in the United States: Trends From the Surveillance, Epidemiology, and End Results Program. Journal of Urology, 176, 2397-2400.

https://doi.org/10.1016/j.juro.2006.07.144

[4] Eke, N. and Echem, R.C. (2003) Nephrectomy at the University of Port Harcourt Teaching Hospital: A Ten-Year Experience. African Journal of Medicine and Medical Sciences, 32, 173-177.

[5] Rafique, M. (2007) Nephrectomy: Indications, Complications and Mortality in 154 Consecutive Patients. Journal of Pakistan Medical Association, 57, 308-311.

[6] Kercher, K.W., Heniford, B.T., Matthews, B.D., Smith, T.I., Lincourt, A.E., Hayes, D.H., et al. (2003) Laparoscopic versus Open Nephrectomy in 210 Consecutive Patients: Outcomes, Cost, and Changes in Practice Patterns. Surgical Endoscopy, 17, 1889-1895. https://doi.org/10.1007/s00464-003-8808-3

[7] Badmus, T.A., Salako, A.A., Sanusi, A.A., Arogundade, F.A., Oseni, G.O. and Yusuf, B.M. (2008) Adult Nephrectomy: Our Experience at Ile-Ife. Nigerian Journal of Clinical Practice, 11, 121-126.

[8] Badmus, T.A., Salako, A.A., Arogundade, F.A., Sanusi, A.A., Adesunkanmi, A.R.K., Oyebamiji, E.O., et al. (2008) Malignant Renal Tumors in Adults: A Ten-Year Review in a Nigerian Hospital. Saudi Journal of Kidney Diseases and Transplantation: An Official Publication of the Saudi Center for Organ Transplantation, Saudi Arabia, 19, 120-126.

[9] Beisland, C., Medby, P.C., Sander, S. and Beisland, H.O. (2000) Nephrectomy: Indications, Complications and Postoperative Mortality in 646 Consecutive Patients. European Urology, 37, 58-64. https://doi.org/10.1159/000020101

[10] Ballesteros Sampol, J.J. (2006) Indications, Morbidity and Mortality of the Open Nephrectomy. Analyses of 681 Cases and Bibliographic Review. Archivos Españoles de Urología, 59, 59-70. https://doi.org/10.4321/S0004-06142006000100009

[11] Datta, B., Moitra, T., Chaudhury, D.N. and Halder, B. (2012) Analysis of 88 Nephrectomies in a Rural Tertiary Care Center of India. Saudi Journal of Kidney Diseases and Transplantation, 23, 409.

[12] Ghalayini, I.F. (2002) Pathological Spectrum of Nephrectomies in a General Hos- 
pital. Asian Journal of Surgery, 25, 163-169.

https://doi.org/10.1016/S1015-9584(09)60167-6

[13] Rini, B.I., Campbell, S.C. and Escudier, B. (2009) Renal Cell Carcinoma. The Lancet, 373, 1119-1132. https://doi.org/10.1016/S0140-6736(09)60229-4

[14] Cao, Y., Paner, G.P., Perry, K.T., Flanigan, R.C., Campbell, S.C. and Picken, M.M. (2005) Renal Neoplasms in Younger Adults: Analysis of 112 Tumors from a Single Institution According to the New 2004 World Health Organization Classification and 2002 American Joint Committee on Cancer Staging System. Archives of Pathology \& Laboratory Medicine, 129, 487-491.

[15] Ahmed, M., Oyelowo, N., Bello, A., Lawal, A.T., Maitama, H.Y., Abdulsalam, K., et al. (2018) Peculiarities of Renal Cell Carcinoma in Young Adults. Archives of International Surgery, 8, 59. https://doi.org/10.4103/ais.ais_33_18

[16] Cassell, A., Jalloh, M., Yunusa, B., Ndoye, M., Mbodji, M.M., Diallo, A., et al. (2019) Management of Renal Cell Carcinoma-Current Practice in Sub-Saharan Africa. Journal of Kidney Cancer and VHL, 6, 1. https://doi.org/10.15586/jkcvhl.2019.122

[17] Andualem, D., Teklebrihan, B. and Wuletaw, C. (2012) Indications, Complications and Mortality of Nephrectomy in Tikur Anbesa General Specialized Hospital. East and Central African Journal of Surgery, 17, 92-97.

[18] Landis, S.H., Murray, T., Bolden, S. and Wingo, P.A. (1999) Cancer Statistics, 1999. CA: A Cancer Journal for Clinicians, 49, 8-31.

https://doi.org/10.3322/canjclin.49.1.8

[19] Tijani, K.H., Anunobi, C.C., Ezenwa, E.V., Lawal, A., Habeebu, M.Y.M., Jeje, E.A., et al. (2012) Adult Renal Cell Carcinoma in Lagos: Experience and Challenges at the Lagos University Teaching Hospital. African Journal of Urology, 18, 20-23. https://doi.org/10.1016/j.afju.2012.04.005

[20] Ekeke, O.N. and Amusan, O.E. (2018) Open Nephrectomy: Experience in a Nigerian Teaching Hospital. Journal of Advances in Medicine and Medical Research, 24, 1-8. https://doi.org/10.9734/JAMMR/2017/38766

[21] Patard, J.-J. (2009) Incidental Renal Tumours. Current Opinion in Urology, 19, 454. https://doi.org/10.1097/MOU.0b013e32832f0ccd

[22] Modi, S., et al. (2016) Adult Wilms' Tumour: Case Report and Review of Literature. Journal of Kidney Cancer and VHL, 3, 1-7. https://www.ncbi.nlm.nih.gov/pmc/articles/PMC5347375

[23] Ahlering, T.E., Boyd, S.D., Hamilton, C.L., Bragin, S.D., Chandrasoma, P.T., Lieskovsky, G., et al. (1985) Emphysematous Pyelonephritis: A 5-Year Experience with 13 Patients. Journal of Urology, 134, 1086-1088. https://doi.org/10.1016/S0022-5347(17)47635-X

[24] Cloutier, V., Capitanio, U., Zini, L., Perrotte, P., Jeldres, C., Shariat, S.F., et al. (2009) Thirty-Day Mortality after Nephrectomy: Clinical Implications for Informed Consent. European Urology, 56, 998-1005. https://doi.org/10.1016/j.eururo.2008.11.023

\section{Abbreviations \\ KATH-Komfo Anokye Teaching Hospital \\ PUJO-Pelvi-Ureteric Junction Obstruction \\ RCC-Renal Cell Carcinoma}

